Artigo

\title{
Movimentos na Educação Matemática: tremores perfurantes nas verdades instituídas
}

\author{
Movements in Mathematics Education: piercing tremors in the established truths \\ Movimientos en la Educación Matemática: temblores penetrantes en las verdades \\ establecidas
}

\section{Resumo}

\author{
Claudia Glavam Duarte ${ }^{1}$ \\ [0000-0002-8608-5855] \\ Kátia Liége Nunes Gonçalves² \\ (iD) [0000-0002-6138-7654] \\ Luciane Mulazani dos Santos ${ }^{3}$ \\ [0000-0001-7617-7310]
}

Este artigo constrói - enquanto se faz - compreensões das autoras sobre uma Filosofia da Diferença para/na/da/sobre Educação Matemática, a partir de movimentos de pesquisa e de prática - de academia e de vida [de ser, de estar e de haver] - EXpostos nos artigos do Boletim online de Educação Matemática - BOEM que foram publicados na Edição Temática Educação Matemática e Filosofia da Diferença, em novembro de 2020 , no número dezessete do volume oito. A provocação sobre tremores perfurantes nas verdades instituídas é nossa! É nossa, mas só despertada graças às dezesseis contribuições de colegas professores com/em formação, cujos textos colocam em evidência experiências, teorias e ideias sobre temas relacionados ao (des)foco da edição. Como resultado, apresentamos um convite à leitura e a reflexões para ampliação de compreensões a respeito da Filosofia da Diferença e de suas relações com a Educação Matemática.

Palavras-chave: Educação Matemática. Produções acadêmicas. Diferença.

\begin{abstract}
This article constructs - as it is done - the authors' understandings about a Philosophy of Difference to/at/of/about Mathematics Education, from research and practice movements - from academia and life [to being, to having] - exposed in the articles of the Online Bulletin of Mathematics Education BOEM that were published in the Thematic Edition Mathematics Education and Philosophy of Difference, in November 2020, at number seventeen of volume eight. The provocation about piercing tremors in the established truths is ours! It is ours, but only awakened thanks to the sixteen contributions of teachers and researchers, whose texts highlight experiences, theories and ideas on topics related to the focus of the edition. As a result, we present an invitation to reading and reflections to broaden understandings about the Philosophy of Difference and its relations with Mathematics Education.
\end{abstract}

Keywords: Mathematics Education. Academic productions. Difference.

1 claudiaglavam@hotmail.com, Doutora em Educação, Professora Associada, Universidade Federal do Rio Grande do Sul - Campus Litoral Norte, Tramandaí/RS/Brasil.

${ }^{2}$ liegekatia@gmail.com, Doutora em Educação em Ciências e Matemáticas, Professora, Universidade Federal do Pará - Campus Castanhal, Castanhal/PA/Brasil.

${ }^{3}$ Iuciane.mulazani@udesc.br, Doutora em Educação, Professora Associada, Universidade do Estado de Santa Catarina - Centro de Ciências Humanas e da Educação, Florianópolis/SC/Brasil. 


\title{
Resumen
}

Este artículo construye - mientras se hace - las comprensiones de los autores sobre una Filosofía de la diferencia para / en / sobre la Educación Matemática, a partir de movimientos de investigación y práctica - de la academia y la vida [de ser y tener] - expuestos en los artículos del Boletín online de Educación Matemática - BOEM que fueron publicados en la Edición Temática Educación Matemática y Filosofía de la Diferencia, en noviembre de 2020, en el decimoséptimo volumen ocho. iLa provocación de los temblores penetrantes en las verdades instituidas es nuestra! Es nuestro, pero sólo despertado gracias a las dieciséis aportaciones de compañeros profesores e investigadores, cuyos textos destacan experiencias, teorías e ideas sobre temas relacionados con el foco de la edición. Como resultado, presentamos una invitación a leer y reflexionar para ampliar la comprensión sobre la Filosofía de la Diferencia y sus relaciones con la Educación Matemática.

Palabras claves: Educación Matemática. Producciones académicas. Diferencia.

\author{
"É porque nada é igual, \\ é porque tudo se banha \\ em sua diferença, \\ em sua dessemelhança \\ e em sua desigualdade, \\ mesmo consigo, \\ que tudo retorna." \\ (DELEUZE, 2006, p. 342)
}

Quais são as razões que levam à crença de que a IDENtidade é superior à diferença?

Que o "mesmo" é superior ao "diferente"?

Ainda que pensemos como Deleuze (2006, p. 361), que concordemos que "tudo o que se passa e aparece é correlativo de ordens de diferenças: diferença de nível, de temperatura, de pressão, de tensão, de potencial, diferença de intensidade", ainda assim, em grande parte dos nossos modos de estar no mundo, mais nos conforta acreditar - e desejar - na identidade e não na DIFEREnça.

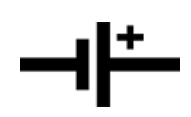

Educação Matemática e Filosofia da Diferença foi uma abertura aos deVIRes da nossa área. DeVIRes que nos arremessam à ANORMALidade para pensarmos a/uma/na Educação Matemática em que o outro se encontra em si mesmo, abrindo-se às outras forças coletivas.

Aos leitores e leitoras, contamos que construímos esta proposta a partir de um desEncontro de vidaS que tiVemos em uma banca docente realizada no campus Litoral Norte da Universidade Federal do Rio Grande do Sul, na cidade de Tramandaí em abril de 2019. E assim foi... passado esse tempo, com uma pandemia de COVID-19 no meio do caminho, do Sul ao Norte... de Tramandaí à Castanhal, passando por Florianópolis... fomos acolhidas, moVidas, turbilhoNadas e nos reFUGlamos em pensamentos rizomáticos para provocAr a comunidade com a publicação desta Edição Temática do Boletim online de Educação 
Matemática: Educação Matemática e Filosofia da Diferença, número 17, volume 8, de novembro de 2020.

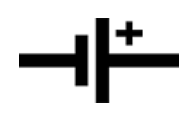

Se, em grande parte das situações de mundo, a oposição entre identidade e diferença governa modos de pensar, para esta edição temática ansiamos encontrar interlocutores que compartilhassem ideias e produções acadêmicas sobre rompimentos com esse pensamento. E assim se deu. Podemos então dizer que os textos aqui publicados - nossos encontros com os autores e autoras que aceitaram nossos convites ao desafio da publicação desta edição expressam modos de ser, estar e pensar a/uma/na Educação Matemática de atuação docente em caminhAres da Filosofia da Diferença:

$-H^{+}$nas universidades: Universidade de São Paulo (USP), Universidade do Estado de Santa Catarina (UDESC), Universidade Estadual de Ponta Grossa (UEPG), Universidade Federal de Mato Grosso do Sul (UFMS), Universidade Federal de Minas Gerais (UFMG), Universidade Federal de Pelotas (UFPel), Universidade Federal de Pernambuco (UFPE), Universidade Federal de Santa Catarina (UFSC), Universidade Federal de São Carlos (UFSCAR), Universidade Federal do Rio Grande (FURG), Universidade Federal do Pará e Universidade Federal do Rio Grande do Sul (UFRGS);

$\boldsymbol{H}^{+}$em um Instituto da Rede Federal de Educação Profissional, Científica e Tecnológica: o Instituto Federal Goiano (IFGoiano);

$-H^{+}$em escolas das redes municipais de educação de Florianópolis/SC, de Porto Alegre/RS e de Pelotas/RS;

$\dashv+$ em escolas da rede estadual de educação do Rio Grande do Sul;

$\dashv+$ em espaços de coordenação da Secretaria de Educação de Pernambuco;

$\neg \uparrow^{+}$no Colégio Militar de Porto Alegre...

$\dashv H^{+}$... como representações de cursos de graduação e de pós-graduação...

$H^{+}$de campos profissionais dos Ensinos Fundamental, Médio e Superior dos Estados: Rio Grande do Sul, Goiás, Santa Catarina, Pernambuco, São Paulo, Paraná, Mato Grosso do Sul, Minas Gerais e Pará. 


\section{QUe DIFERENÇAS nos unem-separam?}

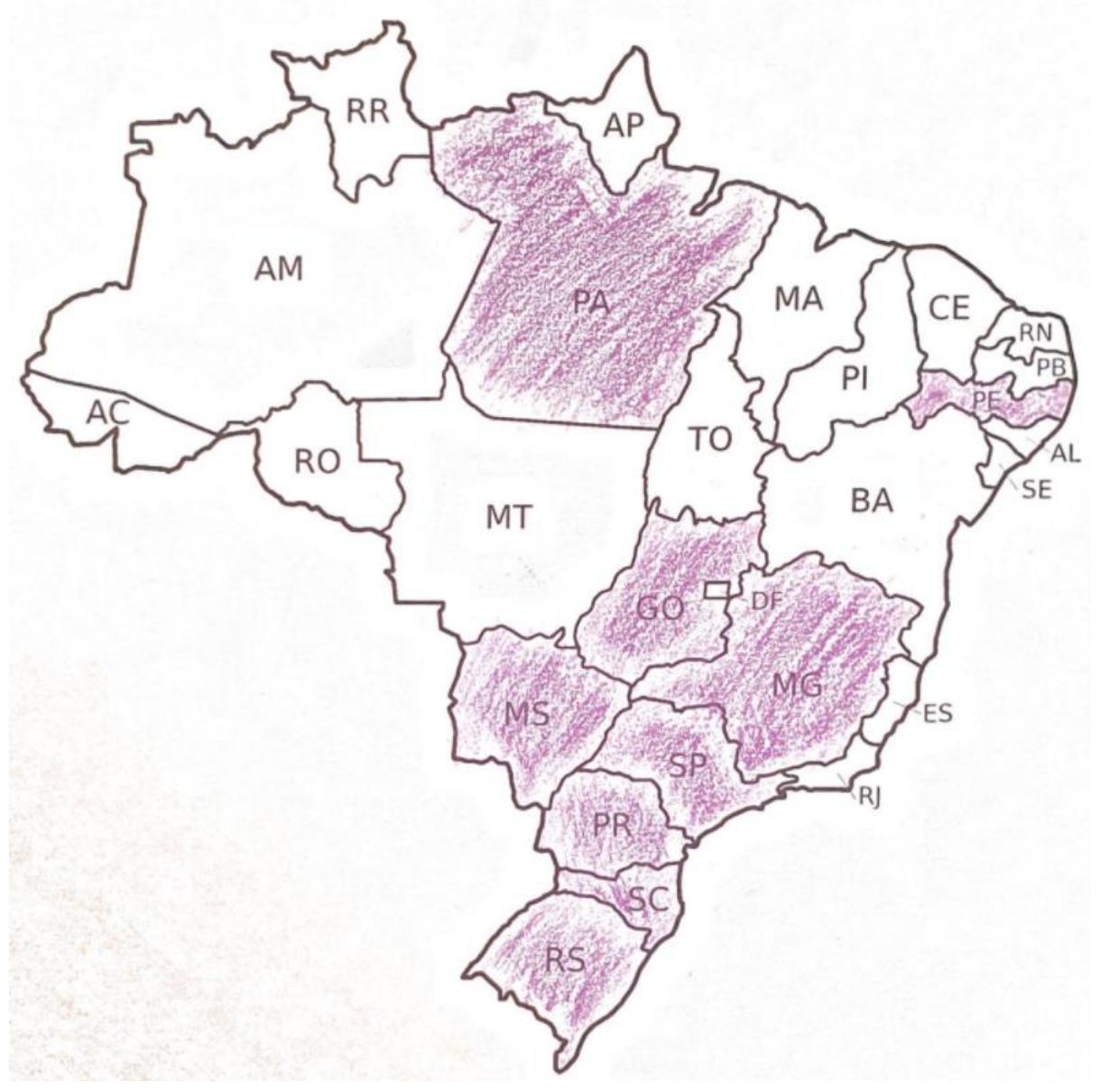

Que IDENTIDADES nos unem-separam?

\section{Educação.}

MATEMÁTICA.

Educação e Matemática e ...

Educação Matemática. Território de pesquisa, de desenvolvimento de práticas, de ensino, de aprendizagem ou de outras dimensões que nos empurram aos olhAres desConfiados. Escutamos sobre provocações da/para/na/pela Educação Matemática as quais, com seus moviMentos entre as identidades e DIFERENÇAS, nos impulsionam a pensar sobre a suspeição de discursos hegemônicos, de pensamentos dominantes e de regimes de verdade em meio às condições de poder, racionalidades, digressões, emergências, potência, resistência, força, formação e conformação, invenção, tecnologias, escritas e reescritas de si. 
Insatisfação, contraConduta, reVer, reEscrever-se, restringir, problematizar, dobrar, devir, exerCitar, rachar, manTer, desTerritorializar, trilhar, policiar, rizoma $R$, deCifrar. Com esses moVimentos, comPartilhamos sobre desenvolvimento de territórios para a Educação Matemática com tendências às modificações na forma de rascunhAr a VIDA, de ser e de estar no mundo.

\begin{tabular}{|c|c|c|c|c|c|c|c|c|c|c|c|c|c|c|c|c|c|c|c|c|c|c|c|}
\hline \multicolumn{24}{|c|}{16 moviMentos de Filosofia da Diferença e Educação Matemática } \\
\hline Y & I & D & $\mathrm{S}$ & $\mathrm{C}$ & 0 & $\mathrm{~N}$ & $\mathrm{~T}$ & $\mathrm{R}$ & A & $\mathrm{C}$ & 0 & $\mathrm{~N}$ & $\mathrm{D}$ & & $U$ & $\mathrm{~T}$ & A & I & $\mathrm{H}$ & H $R$ & $\mathrm{R}$ & S & E \\
\hline D & $\mathrm{S}$ & G & I & $\mathrm{T}$ & L & w & $\mathrm{E}$ & $\mathrm{H}$ & $P$ & $\mathrm{~N}$ & $E$ & $U$ & $\mathrm{E}$ & & $S$ & $P$ & A & $E$ & $\mathrm{~N}$ & $\begin{array}{lll}N & T\end{array}$ & $\mathrm{~T}$ & Y & $\mathrm{T}$ \\
\hline I & $\mathrm{R}$ & I & $R$ & $Y$ & $M$ & $\mathrm{H}$ & $\mathrm{T}$ & $S$ & $\mathrm{R}$ & $\mathrm{H}$ & $M$ & $C$ & w & & $\mathrm{H}$ & 0 & I & W & 10 & 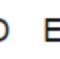 & $E$ & $A$ & $E$ \\
\hline$R$ & $S$ & $E$ & B & $T$ & $\mathrm{H}$ & $\mathrm{R}$ & $E$ & I & 0 & $\mathrm{~N}$ & $\mathrm{R}$ & $E$ & I & 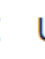 & U & L & $S$ & $U$ & $D$ & 5 & $S$ & 0 & $\mathrm{~N}$ \\
\hline$E$ & B & $\mathrm{T}$ & $E$ & $\mathrm{~L}$ & 0 & $\mathrm{E}$ & $R$ & L & B & $\tilde{A}$ & $\mathrm{~T}$ & $A$ & $D$ & & $\mathrm{R}$ & I & I & $\mathrm{H}$ & $M$ & $1 \mathrm{E}$ & $E$ & 0 & $E$ \\
\hline $\mathrm{N}$ & $\mathrm{N}$ & $Y$ & A & C & $\mathrm{R}$ & $\mathrm{E}$ & I & $D$ & $\mathrm{~L}$ & $\mathrm{~L}$ & Ç & 0 & $\mathrm{H}$ & & $A$ & C & U & $\mathrm{R}$ & $\mathrm{T}$ & TE & $E$ & $E$ & $T$ \\
\hline $\mathrm{H}$ & $\mathrm{R}$ & $Y$ & $\mathrm{~T}$ & $\mathrm{~S}$ & $C$ & $S$ & G & $\mathrm{V}$ & $\mathrm{E}$ & G & B & $A$ & $\mathrm{~L}$ & 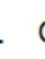 & $c$ & I & $E$ & $Y$ & $\mathrm{~T}$ & $\Gamma_{T}$ & $\mathrm{~T}$ & $D$ & G \\
\hline$E$ & B & $S$ & D & $\mathrm{H}$ & $\mathrm{H}$ & C & $\mathrm{N}$ & $F$ & $M$ & $\mathrm{R}$ & $\mathrm{N}$ & $M$ & $F$ & & G & A & $\mathrm{s}$ & $E$ & $\mathrm{Y}$ & l & $W$ & $\mathrm{~N}$ & 0 \\
\hline$Y$ & w & $S$ & 0 & $\mathrm{~J}$ & $S$ & $\mathrm{R}$ & I & C & $A$ & $\mathrm{~T}$ & $\mathrm{~N}$ & $\mathrm{~K}$ & $\mathrm{R}$ & & $S$ & $\mathrm{R}$ & $\mathrm{R}$ & $A$ & $\mathrm{Y}$ & 10 & 0 & M & $\mathrm{N}$ \\
\hline$E$ & $\mathrm{H}$ & $P$ & S & $\mathrm{T}$ & $M$ & $E$ & $\mathrm{R}$ & $\mathrm{R}$ & $\mathrm{T}$ & $D$ & $R$ & $A$ & $\mathrm{H}$ & & $\mathrm{L}$ & I & $\mathrm{R}$ & $\mathrm{T}$ & W & $V E$ & $E$ & $A$ & M \\
\hline $\mathrm{N}$ & $P$ & $E$ & 0 & I & $\mathrm{H}$ & V & $\mathrm{T}$ & I & I & $S$ & G & $D$ & A & & I & V & $T$ & $A$ & L & I & I & $\mathrm{N}$ & $U$ \\
\hline$E$ & $P$ & $E$ & $R$ & $C$ & A & $E$ & $S$ & B & z & $E$ & $\mathrm{R}$ & $\mathrm{T}$ & I & & $E$ & $E$ & $A$ & $A$ & V & 10 & 0 & $\mathrm{~T}$ & $T$ \\
\hline W & $M$ & $E$ & $E$ & 0 & $S$ & $\mathrm{R}$ & $\mathrm{E}$ & A & $A$ & 0 & $\mathrm{E}$ & $\mathrm{K}$ & $\mathrm{E}$ & & $\mathrm{H}$ & D & G & $A$ & $S$ & $5 \quad T$ & $\mathrm{~T}$ & $E$ & $E$ \\
\hline$A$ & $\mathrm{~L}$ & $D$ & $E$ & C & I & $F$ & $\mathrm{R}$ & $A$ & $\mathrm{R}$ & $P$ & $M$ & $\mathrm{~T}$ & $\mathrm{R}$ & & $F$ & $D$ & $D$ & $E$ & L & $-N$ & $\mathrm{~N}$ & $\mathrm{R}$ & A \\
\hline$D$ & $E$ & $S$ & $\mathrm{~T}$ & $E$ & $\mathrm{R}$ & $\mathrm{R}$ & I & $\mathrm{T}$ & 0 & $\mathrm{R}$ & I & $A$ & $\mathrm{~L}$ & & I & $z$ & $A$ & $\mathrm{R}$ & $\mathrm{R}$ & $2 \mathrm{~A}$ & A & I & $\mathrm{N}$ \\
\hline$A$ & $\mathrm{~L}$ & U & L & $\mathrm{H}$ & $\mathrm{E}$ & $X$ & $E$ & $\mathrm{R}$ & C & I & $\mathrm{T}$ & $A$ & $\mathrm{R}$ & & $N$ & $E$ & I & $P$ & $\mathrm{~K}$ & $\begin{array}{ll}K & T\end{array}$ & $\mathrm{~T}$ & I & B \\
\hline
\end{tabular}

$\dashv H^{+} \quad$ Movimento 1 - insatisfação

DesContente, desPrazer...

Estarem insatisfeitos com as trepidações do pensamento. Foi o que permitiu à Maria Carolina Magnus Machado e Ademir Caldeira um deslocamento nas formas de perceber as verdades de uma contemporaneidade. Espreitando a emergência da Modelagem Matemática na Educação Matemática nos conduz à problematização do caráter salvacionista presente no discurso da Modelagem Matemática. Assim, desConfiados, os autores questionam suas próprias pretensões ao desenvolverem um território que seria singular para a Educação Matemática.

DesConFiados... fiados por outros fios, os autores nos propõem uma digressão a fim de entendermos algumas das condições de possibilidade para a emergência deste discurso. No embate de forças desta emergência estão dois enunciados - "(i) os alunos têm dificuldade na aprendizagem da Matemática e (ii) a Matemática é distante da realidade" - que 
provavelmente contribuíram para que a Modelagem Matemática se tornasse tema de conversa entre os docentes preocupados em resolver os problemas acima detectados. A dificuldade dos estudantes estaria alicerçada na própria concepção do conhecimento matemático, ou seja, nas suas características. Dito de outro modo, a exigência de certa linearidade dos conhecimentos, a necessidade de ir do mais simples ao mais complexo, entre outras, ocasionariam tais dificuldades que o currículo espiralado da Modelagem poderia resolver. Nessa perspectiva, a Modelagem propiciaria outras estratégias para desenvolver 0 processo de ensino e aprendizagem dos conteúdos escolares. No entanto, as novas estratégias postas a operar não passariam de uma variação do mesmo, pois "funcionariam como uma engrenagem na busca pelo melhor funcionamento daquilo que está posto".

\title{
$\rightarrow+$ Movimento 2 - contraConduta
}

\author{
Atitude, \\ práticas de combate \\ aos modos \\ estabelecidos \\ e NORMAlizados.
}

A contraConduta das autoras Letiane Oliveira da Fonseca e Márcia Souza da Fonseca no artigo Etnomatemática, jogos de linguagem e movimentos de contraconduta de mulheres no ocupar o Quadrado, ao suspeitarem dos "discursos hegemonicamente contados como ciência", estremece a linguagem carregada de intenções UN/versais.

Acompanhadas das histórias de Wilma, Ana Maria, Gilda Maria e Ladi Cristine, mulheres que ocuparam a região do Quadrado na cidade de Pelotas, no Rio Grande do Sul, as autoras dão visibilidade à ocupação não só do território da localidade do Quadrado, mas, também, do território dos pretensos significados únicos da linguagem. Ademais, ao utilizaremse de ferramentas wittgensteinianas, as autoras sinalizam o quanto a racionalidade, ser e estar no mundo, está enraizada às especificidades das formas de vidaS e nos jogos de linguagem que lhes são inerentes. Assim, a utilização de expressões próprias que regulam aS vidaS, investigada pelas autoras, apontam para a racionalidade que as alicerça. Desfaz-se a isomorfia entre linguagem e mundo. Não há como pretender um fundamento UN/versal para os nossos pensamentos e ações. Privilegia-se, a partir de Wittgenstein, então "a interação ao invés da representação" (DUARTE; FARIA, 2017, p. 87). A Matemática não escapa dessa premissa, pois a busca por uma essência matemática foi uma ilusão que povoou a cabeça de filósofos e matemáticos.

$-H^{+} \quad$ Movimento 3 - rever

\author{
Ver novaMente; \\ ver mais uma, \\ deMorar-se nos detalhes \\ para ver diferente.
}

Assumindo que qualquer tipo de essência é mera ilusão, porém com outros olhAres teóricos, o artigo proposto por Júlio César Gomes Oliveira e Marcio Antonio da Silva dá 
visibilidade ao caráter contingente e arbitrário das verdades que nos circundam, nos atravessam e nos constituem. Trata-se especialmente de uma discussão que envolve a constituição de sujeitos, ou melhor, da construção de posições, no campo educativo especificamente da Educação Matemática que, por meio de enunciados instituídos pelo discurso da Educação Matemática Crítica interpelam professores e estudantes.

Assim, o artigo Pensando de outro modo um tipo de conteúdo proposto pela Educação Matemática Crítica dentro da educação matemática pergunta como esse discurso opera a necessidade de formação do estudante crítico, bem como quais são os mecanismos colocados à disposição para essa formação. Pensam esse dito por entre indagações:

Como provocar em meio a formAção um sujeito crítico que possa contribuir socialmente, mas que precisa, acima de tudo, se autogovernar?

De que maneiras a maquinaria escolar reage a tal necessidade?

Quais os caminhos a serem perCorridos?

Que saberes o estudante precisa apreender para desenvolver sua criticidade chegando a ser inventivo?

Que movimento instigador possibilita o desenvolvimento a criticidade e/ou inventividade do estudante?

Quais disparadores levam um estudante ter um pensamento crítico?

Interessante observar, neste artigo, o lugar que ocupa a Matemática no discurso da Educação Matemática Crítica: "indivíduo é alguém que precisa, antes de qualquer coisa, saber matemática." Trata-se de algo tal como "diga-me o que sabes de matemática e te direi quem és".

Assim, circularMente, a Matemática empodera os sujeitos que transFormam a realidade que necessita da Matemática para continuar seu processo de transFormAção. Para isso, há necessidade de conteúdos cujo foco esteja na vida dos estudantes, destacando problemas relevantes e interessantes que abordem questões sociais. No entanto, segundo os autores, o problema a ser enfrentado precisa ser de cunho social, pois assim, os estudantes assumem os problemas como seus, mobilizando maneiras outras de pensar a vida... VIDAS.

As prescrições, as regras a serem seguidas são tantas que tornam, muitas vezes, um fardo pesado de se carregar visto tantos os penduricalhos que são exigidos dos docentes.

\footnotetext{
"A aula está dada". - afirmava, com sua voz empostada, Pendurela aos seus alunos ao bater do sinal para encerrar o segundo horário daquela manhã. Pendurela dá aulas de Matemática há alguns anos e sempre orgulhou-se em afirmar coisas do tipo: "Na minhas aulas mando eu.", "Hoje preparei uma coisa diferente.", "Não podemos parar, temos que terminar o conteúdo", "Eu trabalho com a realidade dos alunos", etc. Hoje, porém, mostra-se fatigada, sem energias, sem vontade de continuar lecionando. Santa Pendurela, tão singela com seus penduricalhos. Talvez nem saiba o quanto lhes pesam, talvez nem imagine que não os tenha que carregar, talvez nem tenha pensado que nunca foram seus (AURICH, 2017, p. 10).
}

Mostrar que não são seus estes penduricalhos talvez seja a contribuição dos autores, mesmo que não as declarem, ao evidenciarem as exigências propostas por um currículo crítico. 


\section{$\neg H^{+} \quad$ Movimento 4 - reescrever-se}

"[...] experimentação filosófica que acontece ao recolher instantaneidades de uma docência em meio à vida"

As prescrições, as regras a serem seguidas são tantas que tornam, muitas vezes, um peso que reTira as forças do corpo, visto a quantidade de penduricalhos que são exigidos dos docentes. Assim, Grace Aurich e Samuel Belo evidenciam, com o artigo intitulado Aula 1 de Pendurela: Como inventar uma docência em matemática pela reescrita de si?, o quanto as práticas discursivas acabam forjando tais penduricalhos e em efeito, o próprio sujeito docente.

Mostrar que não são seus estes penduricalhos é contribuição dos autores, ao evidenciarem o quanto os regimes de verdade do presente-hoje-amanhã, constituídos pelos saberes de especialistas, prescrevem modo de atuar e de ser professor de Matemática. No entanto, apontam os autores, é possível mover-se entre tais verdades para pensar um outro processo de invenção de si.

Trata-se então, de constituir escritas e reescritas de si por meio dos desEncontros com as instantaneidades da vida, de deixar-se afectar pelo inEsperado e, quem sabe assim produzir diferentes sentidos para e pela docência. Para essa reEscrita de si são propostos fragmentos do vidário de Pendurela, da professora de Matemática, que ao debruçar-se sobre os instantâneos da vida torna opaco os clichês que até então a moviam e, dessa forma, produz um espaço onde é possível variar, inventar e diferir os sentidos já dados para docência em Matemática.

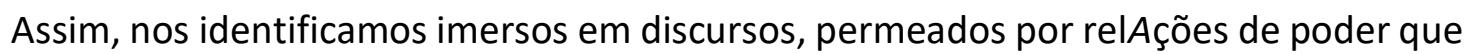
integram a possibilidade de fazermos cortes, rupturas, nas redes que nos tecem. Quem sabe, possamos nos constituir de outros jeitos, um intenso entrecruzar, ser metamorfósico, buscar em si um "querer libertador e aterrorizador", que "atrai a vontade de inventar, a vontade de não parar, vontade de querer, a vontade de liberdade, a vontade de alegria, a vontade de nada, a vontade de morrer-viver, a vontade de ensinar-saber-aprender, a vontade de amar..." (GONÇALVES, 2018, p. 129).

\section{$-H^{+} \quad$ Movimento 5 - restringir}

Impedir, não deiXar, Não Pode!!!

E quando restringir, impedir tornam-se mola propulsora para a criação! Restrições matemáticas e criação literária: o paradoxo do pensamento da diferença na Literatura Potencial, de Suelen Assunção Santos e Josaine de Moura, apontam para a multiplicação dos sentidos quando restrições são postas e impedem o automatismo da escrita.

A Literatura Potencial, criada pelo grupo OuLiPo, como objeto de investigação das autoras, desmontam entendimentos a respeito da inspiração para a composição da escrita, pois essa seria uma obediência a regras que nos passam desPercebidas e que ignoramos. Daí reDobrar a força da inspiração sobre ela mesma, impedindo-a de seguir seu fluxo parece ser a aposta desse grupo de literatos. 
Mas, e Matemática? O que ela possibilita? A proposta do anulipismo, ou seja, colocar restrições matemáticas em textos já produzidos, parece ser um indicativo de resposta a essa pergunta. Parece-nos que a Matemática faz "um filho pelas costas", como diria Deleuze (1992) nos sentidos disponibilizados pelos textos anteriores.

\section{$\neg I^{+} \quad$ Movimento 6 - problematizar}

TornAr problema, pensAr perguntAndo.

Música e Matemática, relação bastante conhecida e provocada por escrituras de Deleuze (2002) quando indaga: Em que a filosofia pode servir a matemáticos ou mesmo a músicos: mesmo e sobretudo quando ela não fala de música ou de matemática? Ensinam-se frações, medidas, fazem-se paródias para a memorização de conceitos, no entanto, parece que esse encontro não dança, parafraseando Nietzsche (2001). Nesse sentido, Alice Stephanie Tapia Sartori e Juliano Espezim Soares Faria constroem o artigo Problematizando as relações entre Matemática e Música na Educação Matemática para desOrganizar a relação "naturalmente" evocada nesta relação. Busca-se, então, pensar o ritornelo como possibilidade de fuga para compor novos agenciamentos para uma reTerritorialização no campo da Educação Matemática. Tais agenciamentos fogem dos já propostos, articulações com a realidade, trazer ludicidade às aulas, contextualizar os conceitos, entre outros. Buscase na própria língua da matéria de estudos a potência para a aprendizagem da Matemática.

\section{$\neg H^{+} \quad$ Movimento 7 - dobrar}

Curvar, forçAr sobre si mesmo...

O artigo intitulado Matemática difícil: discursos, muros e monstros de Luana Rafaela da Silva Costa e Simone Moura Queiroz nos possibilita pensar no discurso de que a matemática difícil é monstruosa e que, em efeito, constitui sujeitos que possuem ojeriza por esta área do saber. O texto, a partir de entrevistas com professores e estudantes, evidencia o quanto, os primeiros acabam reForçando este discurso e criando muros difíceis de serem escalados e/ou ultrapassados. No entanto, as autoras rEsistem e sugerem a dobra como estratégia, ou seja, dobrar o discurso sobre si mesmo até destruí-lo discursivamente ou, quem sabe, tornar o monstro domável.

\section{$\neg+\quad$ Movimento 8- devir}

Vir a ser, deVIR minoritário, processo de involução, deserto poVOAdo, comPosição de afectos e velocidades. 
Assumindo então, que o sujeito é criação, é comPosição que se dá em meio a forças presentes em discursos e práticas, as autoras Graciela Coelho Andrade de Souza e Simone Moura de Queiroz do artigo intitulado: A constituição de si: uma cartografia das subjetividades no devir professor de matemática dos Anos Iniciais do Ensino Fundamental indaga sobre os processos de subjetivação que atravessam essas professoras quando encontram-se com o saber matemático. Abre-se a possibilidade de visibilizar algumas linhas de força que incidem e perpassam o devir-professor de matemática-dos-anos-iniciais. Assim, identificam-se linhas e as forças provenientes de seus processos de escolarização, dos afectos vivenciados e dos sentimentos erigidos e que sinalizam algumas sedimentações ocorridas. Dar-se conta das forças que desPotencializam a vida se faz necessário para que outras, mais leves e alegres, encontrem espaço para se efetuarem.

\section{$\neg I^{+} \quad$ Movimento 9 - exercitar}

Praticar,
treinar,
esForçar-se

O texto de Patrícia Lima da Silva e Claudia Glavam Duarte intitulado Dos Jogos Olímpicos da Antiguidade às olimpíadas de matemática: a constituição de atletas desconfia das palavras, daquelas que se remetem uma as outras e que replicamos mesmo que o contexto de sua aplicação seja diferenciado. Trata-se de pensar nas Olimpíadas Gregas da Antiguidade e nas Olimpíadas de Matemática. Para isso as autoras fazem a História Gaguejar ao buscar continuidades e desContinuidades entre estes dois eventos tão distantes no tempo. Acompanhadas da perspectiva histórica foucaultianas elas perguntam: o que se passa aí? Por que existem referências aos estudantes medalhistas das olimpíadas como atletas da matemática? Em busca de respostas as autoras apontam alguns desLocamentos e rupturas entre estes dois eventos, tais como a mudança de ênfase do exercício exigido pelas competições, que passa do corpo ao cognitivo, premiAções em diferentes momentos da competição e a própria extensão e pulverização das olímpiadas, entre outros.

No entanto, as aproximações se dão em torno do EXERCITAr-se, do esforçar-se para constituir-se como atleta das competições. Esforçar-se, estar atento ao que se faz, talvez seja o elo e a potência que nos possibilite, chamar os estudantes medalhistas desta competição de "atletas da matemática".

\section{$-H^{+}$Movimento $10-$ rachar}

Abrir, afastando as partes de um todo; fender: rAchar uma árvore.

Gret $A r$, abrir fendas em.

Dividir violentaMente: o raio rachou a palmeira.

Fazer em estilhas, lascar: rachar lenha.

Aceitando essa premissa, será necessário então rachar as palavras, despedaçá-las e estilhaçá-las para, quem sabe, possam dizer outras coisas também para nós, educadores vinculados à Educação Matemática, visto que "não escapamos da linguagem". Virgínia 
Crivellaro Sanchotene e Gilberto Silva dos Santos, com o texto: Rachar as palavras em aulas de matemática: (com)posições de sentidos provocam/cutucam as palavras para que

[...] durem dizendo cada vez coisas distintas, para que uma eternidade sem consolo abra o intervalo entre cada um de seus passos, para que o devir do que é o mesmo seja, em sua volta ao começo, de uma riqueza infinita, para que o porvir seja lido como o que nunca foi escrito... há que se dar às palavras que recebemos. (LARROSA, 2004, p. 15).

Assim, colocam-se sob suspeição as palavras, principalmente aquelas que formam/conFormam o que pode ser dito/estudado/inventado em uma aula de Matemática. Trata-se, como afirma os autores, de "um trabalho de resistência às significações soberanas", que tendem a fixar e a asfixiar outras possibilidades de cri $A$ ção nas aulas de Matemática e que acabam por fissurar "o "mito babélico" de uma linguagem originária comum que resgataria a possibilidade de devolver a suposta unidade que teria sido perdida." (DUARTE, 2012, p. 171).

\section{$-I^{+} \quad$ Movimento 11 - manter}

ConSERvar, policiAR, SALvar.

Mas a polícia INsiste... INvade! Cria ANTÍdotos para manter a supremacia dos modos hegemônicos de ser professor de Matemática e de lidar com esse conhecimento. Inventamse discursos SALVAcionistas, muitos dos quais aludem aos recursos metodológicos, que prometem sanar os males que atravessam o campo educativo. Nas palavras de Luana Rafaela da Silva Costa e Simone Moura Queiroz, trata-se de um Hiperativismo pedagógico composto por discursos que garanTEM resgatar a motivação e o fascínio pela Matemática no ambiente escolar.

\section{$\neg I^{+} \quad$ Movimento 12 - desTerritorializar}

Sair, fug $/ R$

Contrários à força da Educação maior, estatal, que está disposta nas legislações, nas avalições de larga escala e nos grandes projetos totalizantes, João Paulo Risso e Thiago Donda Rodrigues, nos indagam no texto "Desterritorializando a aula de Matemática: o que pode um professor militante no âmbito de uma educação matemática menor?".

O que pode? Pergunta que cata potência! Chama a clandestinidade! Para isso, faz-se necessário o MOVImento de problematizar o "maior" (seja na literatura ou na Educação) que busca estabelecer afirmações generalizáveis e que acabam por se constituir num modelo totalitário na medida em que negam outras formas de literatura/Educação/conhecimento que não se pautam pelos seus princípios epistemológicos e suas regras metodológicas, em que é o lugar instituídos, fixo. Segundo, desTerritorialização, abandono/subversão do território da matemática escolar, para uma reTerritorializAção/invenção de uma educação matemática menor que rompe fronteiras, faz barulho, questiona currículos imexível, saberes e práticas 
escolares hegemônicas. Para este novo território, será preciso abandonar, subverter o professor profeta para que possa emergir um professor militante, insurgente na/com a coletividade para sacodir aS matemáticaS escoLARES.

\section{$-I^{+} \quad$ Movimento 13 - trilhar}

MOVImento, abertura, caminhAR desLocando-se, triturar as placas que indicam um único caminho.

O que pode uma trilha quando pensada no percurso de uma formação que tem como trilheiros professores que ensinam Matemática? A trilha abre caminhos, possibilita desvios, produz trincheiras, abre valetas e acaba por produzir um caminhAR. É o que nos propõem Jussara Brigo e Claudia Regina Flores: Sobre o estudar com professoras que ensinam matemática nos anos iniciais do Ensino Fundamental: a ideia de uma formação-trilha ao evitarem caminhos já abertos, placas de sinalizações com os caminhos a serem seguidos, para fazer emergir um "tipo de contraDispositivo da formação que vê no caminhar e no estudar a possibilidade de "[...] imaginar outros espaços, onde os sujeitos possam andar com os próprios pés e per-correr suas próprias trilhas". Colocam-se sobre a mesa, a matemática, sua língua e inventa-se, cria-se, estuda-se arriscando-se na trilha aberta. Seria um movimento com abertura a deFormação. Abrindo possibilidade ao "não-imitar, o não-modelo, a singularidade, a heterogeneidade, a multiplicidade, a invenção, movimentando-se nomadamente, em fluxos turbilhonares que envolveram uma vida...vidas..." (GONÇALVES, 2018, p. 15).

\section{$\dashv I^{+} \quad$ Movimento $14-$ policiar}

Guardar, vigiar com auxílio da polícia ou conforme os REGULAmentos policiais.

ConTer, refreAr.

No entanto, sempre há os policiamentos!! Isso você pode, isso não te é permitido. Por quê? Porque tem os instrumentos do Estado de prontidão impedindo qualquer fluxo não autorizado. São as perversas avaliações externas, que conduzem, criam sulcos no caminho a ser seguido pelas escolas, professores e estudantes, que João Ricardo Viola dos Santos e Edivagner Souza Santos problematizam no texto avaliações externas, escolas, professores de matemática, máquinas de guerra, aparelhos de estado. Por um lado, controle exacerbado das condutas, relações de poder, pulsão de vida enfrAquecida, por outros MOVImentos de contraConduta, resisTências. Liberdades reguladas e "autonomias vigiadas" e pontos de fuga e força sobre força... Mas como dobrar essa força sobre ela mesma? Como fazê-la ringir até provocar um barulho ensurdecedor? Talvez, fazê-la variar tanto a ponto de não a reconhecer mais. 


\section{$-1+\quad$ Movimento 15 - rizoma(r)}

Fazer rizoMAS, propiciar diferentes conexões, MULT/plicidades

Construir outro plano de imanência para a Educação Matemática. RizomaTizá-lo, extrair as raízes arbóreas que insisTem em se manTer. Eis o desafio proposto por José Rogério Vitkowski no artigo: A Educação Matemática e a fórmula n-1: rizoma e utopia. Trata-se de uma conexão entre a Filosofia da Diferença e a Educação Matemática, especificamente no que tange ao currículo estático, do aprisionamento. Os autores nos instigam a pensar nos pressupostos do currículo arbóreo instalado e nas vãs tentativas de sufocá-lo com a inter/trans/poli/multidisciplinaridade. Outra possibilidade irRompe com o currículo R/zoma, que "voa e metamorfosea como as libélulas, abusa das velocidades e movimentos e... mantem-se na clandestinidade" (GONÇALVES, 2018, p. 41) e que admite diferentes entradas, estabelecendo por vezes, conexões inimaginadas com possibilidade para o outro-novo corta.

\section{$\neg I^{+} \quad$ Movimento $16-$ decifrar}

INTERpretar, desCodiFicar

Colocar de lado a reCognição, a representação, o pensamento já dado. Convite feito por Michela Tuchapesk da Silva e Carolina Tamayo no artigo APRENDER matemáticaS: UM ENCONTRO COM SIGNOS.

Provocações feitas aos estudantes da Licenciatura em Matemática.

Acompanhadas de Deleuze, as autoras mobilizam outros sentidos para a experiência do aprender. Aprende-se com o corpo! Perceptos e afectos entram na ação do aprender, indo além de uma imagem do pensamento-julgamento em que precipita fazer fendas, labutar pela relva, pelas zonas, pelos MOVImentos (GONÇALVES, 2018). Mas, para isso, a dor, a violência causada pelo signo que nos força a pensar, que resiste a um enQUADRAmento, a norma ESTAbelecida.

Eis aí a possibilidade da criação...INVENÇÃO! 
16 MoviMentos de Filosofia da Diferença e Educação Matemática

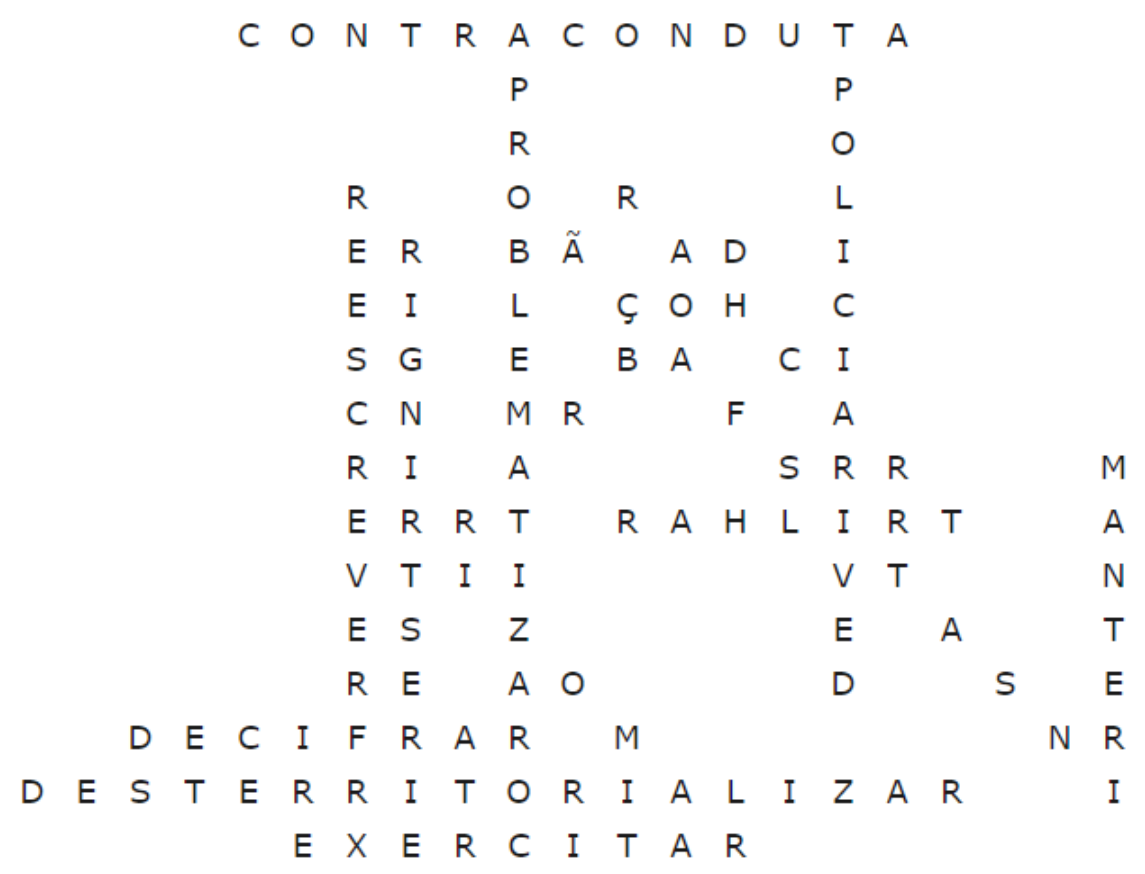

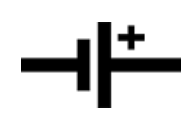

Que os MOVImentos por TR/lhas R/zomáticas das escritas dos artigos publicados cheguem zUnindo aos autores, às autoras, aos leitores e às leitoras fissurando o pensamento. Desejamos um provocar de deslocamentos nas formas de percepção (para suspeição) das verdades estabelecidas naquilo que constituem nossas posições no campo da Educação Matemática. Outras posições. Que não sejam melhores ou piores. E, sim, que sejam diferentes. Que forjam sujeitos docentes em nós, que DesReTerritorializam uma Educação Matemática que faça tremer e abalar verdades e identidades instituídas. Desconfie! Resista! Invente! Chame a irreverência! Precipite vida e VIDAS cheias de fabricações de deVIRes e que possam estar sempre no entre, no meio, na relva. Que DESterritorialize e REterritorializer e DesReTerritorialize! 
É por esse riscar, perFurar pelo meio... da IRreverência da ARte de rua que faz provocAR pensamentos deslizantes; identifica e diferencia; transgride; subverte; coRompe; ex-inclui... aqui o Bansky e seus mistérios de identidade expõem a diferença. Pensar na/para a Matemática e... na/para a Educação e... para/na Educação Matemática e...? EstaCIOnar ou brincAR? Romper, TRANSgredir ou não com o constituÍDO?
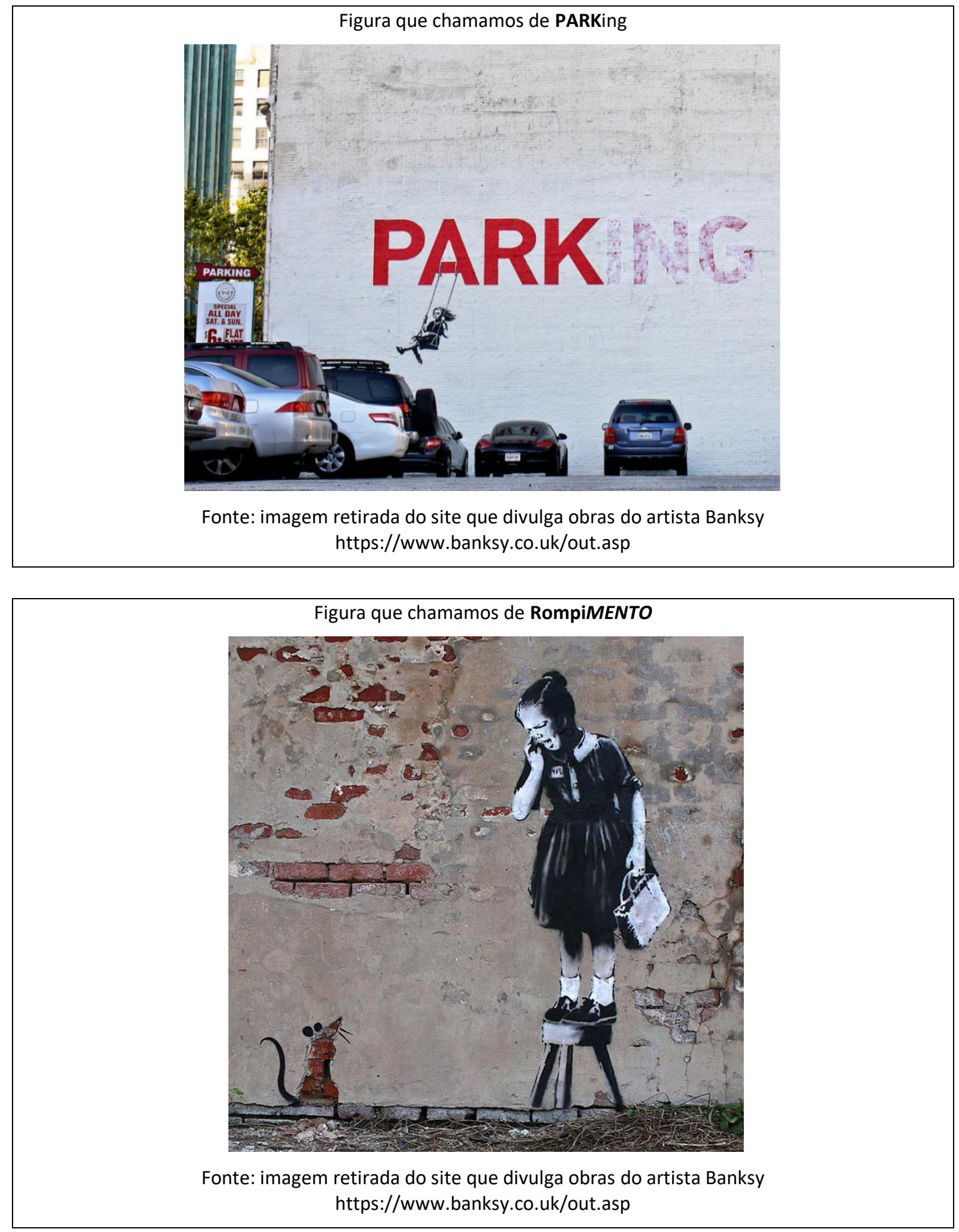


\section{Referências}

DELEUZE, Gilles. Conversações. Trad. Pál Pelbart. São Paulo: Editora 34, 1992.

DELEUZE, G. Em quê a filosofia pode servir a matemáticos ou mesmo a músicos: mesmo e sobre tudo quando ela não fala de música ou de matemática. In: Gilles Deleuze - Educação e Realidade. v. 27, n. 2. Porto Alegre: UFRGS, 2002. p. 225-226.

DELEUZE, Gilles. Diferença e Repetição. Tradução de L. Orlandi e R. Machado. 2.ed. Rio de Janeiro: Graal, 2006.

DUARTE, Claudia Glavam; FARIA, Juliano Espezim Soares. Educação do Campo e Educação Matemática: possíveis entrelaçamentos. Revista Reflexão e Ação, Santa Cruz do Sul, v. 25, n. 1, p. 80 98, Jan./Abr. 2017.

DUARTE, Claudia Glavam. Problematizando a neutralidade e universalidade do conhecimento matemático. Revista Trajetórias Multidisciplinares. - Ed. Esp. XVI Fórum Internacional de Educação ano 3, № 7, - Ago/2012.

GONÇALVES, K. L. N. Nomadismo da Educação Matemática ribeirinha: potências da multiplicidade. 2018. p. 141. Tese (Doutorado em Educação Matemática) - Instituto de Educação Matemática e Científicas, Universidade Federal do Pará, Belém, 2018.

LARROSA, Jorge. Linguagem e educação depois de Babel. Belo Horizonte: Autêntica, 2004.

NIETZSCHE, Friedrich. A Gaia Ciência (tradução de Paulo César de Souza). São Paulo:

Companhia das Letras, 1a ed. 2001. 